\title{
The role of the mini-open thoracoscopic-assisted approach in the management of metastatic spine disease at the thoracolumbar junction
}

\author{
*Vijay M. Ravindra, MD, MSPH, Andrea Brock, MD, AI-Wala Awad, MD, Ricky Kalra, MD, and \\ Meic H. Schmidt, MD, MBA \\ Department of Neurosurgery, Clinical Neurosciences Center and Huntsman Cancer Institute, University of Utah, Salt Lake City, \\ Utah
}

\begin{abstract}
OBJECTIVE Treatment advances have resulted in improved survival for many cancer types, and this, in turn, has led to an increased incidence of metastatic disease, specifically to the vertebral column. Surgical decompression and stabilization prior to radiation therapy have been shown to improve functional outcomes, but anterior access to the thoracolumbar junction may involve open thoracotomy, which can cause significant morbidity. The authors describe the treatment of 12 patients in whom a mini-open thoracoscopic-assisted approach (mini-open TAA) to the thoracolumbar junction was used to treat metastatic disease, with an analysis of outcomes.
\end{abstract}

METHODS The authors reviewed a retrospective cohort of patients treated for thoracolumbar junction metastatic disease with mini-open TAA between 2004 and 2016. Data collection included operative time, estimated blood loss, length of stay, follow-up duration, and pre- and postoperative visual analog scale scores and Frankel grades.

RESULTS Twelve patients underwent a mini-open TAA procedure for metastatic disease at the thoracolumbar junction. The mean age of patients was 59 years (range 53-77 years), mean estimated blood loss was $613 \mathrm{ml}$, and the mean duration of the mini-open TAA procedure was 234 minutes (3.8 hours). The median length of stay in the hospital was 7.5 days (range 5-21 days). All 12 patients had significant improvement in their postoperative pain scores in comparison with their preoperative pain scores $(p<0.001)$. No patients suffered from worsening neurological function after surgery, and of 7 patients who presented with neurological dysfunction, $6(86 \%)$ had an improvement in their Frankel grade after surgery. No patients experienced delayed hardware failure requiring reoperation over a mean follow-up of 10 months (range $1-45$ months).

CONCLUSIONS The mini-open TAA to the thoracolumbar junction for metastatic disease is a durable procedure that has a reduced morbidity rate compared with traditional open thoracotomy for ventral decompression and fusion. It compares well with traditional and novel posterior approaches to the thoracolumbar junction. The authors found a significant improvement in preoperative pain and neurological symptoms that supports greater use of the mini-open TAA for the treatment of complex metastatic disease at the thoracolumbar junction.

http://thejns.org/doi/abs/10.3171/2016.5.FOCUS16162

KEY WORDS thoracoscopic-assisted approach; metastatic; thoracotomy; mini-open TAA

A PPROXIMATELY $70 \%$ of patients with cancer have evidence of metastatic disease at the end of their life..$^{16}$ Treatment advances have led to improved survival rates for many cancer types, but this has led to a greater incidence of metastatic disease, specifically to the vertebral column, which occurs in up to $40 \%$ of patients with evidence of metastatic disease. ${ }^{20,29}$ Additionally, the spine is the most common site for osseous metastatic spread that commonly results in severe, debilitating back pain, spinal deformity, pathological fractures, and spinal cord compression with resultant neurological compromise. ${ }^{20,21}$

Not all patients with spinal metastatic disease develop neurological compromise, but approximately $10 \%-20 \%$ of patients present with symptomatic spinal cord compression. With over 25,000 cases per year, spinal cord injury secondary to metastatic tumor compression is more common than traumatic spinal cord injury. ${ }^{20,21,29}$ The most common location is the thoracic spine (70\%), followed by

ABBREVIATIONS EBL = estimated blood loss; SSI = surgical site infection; TAA = thoracoscopic-assisted approach; VAS = visual analog scale.

SUBMITTED April 1, 2016. ACCEPTED May 24, 2016.

INCLUDE WHEN CITING DOI: 10.3171/2016.5.FOCUS16162.

* Drs. Ravindra and Brock contributed equally to this work. 
the lumbar (20\%) and cervical (10\%) spine. ${ }^{7,12,13}$ For lesions located in the thoracolumbar junction, an overwhelming majority-nearly $85 \%$ - are located ventrally in the vertebral body and epidural space, with only $15 \%$ in posterior elements only. 7,13

The treatment of metastatic disease of the spine involves surgery, radiation therapy, and chemotherapy; surgical decompression and stabilization prior to radiation therapy have been shown to improve functional outcomes. ${ }^{25} \mathrm{Al}$ though posterior decompression and fusion can be a viable option for posteriorly located masses, with a majority of lesions presenting ventrally and causing ventral epidural compression, this can be an inadequate treatment..$^{13,15,25,33}$ Anterior approaches have been developed for more adequate and direct ventral spinal cord decompression. Open procedures involving thoracotomy can have significant morbidity, including chest wall incisional discomfort, difficulty breathing, and pulmonary effusion. Thus, the minimally invasive techniques used in the treatment of thoracic disc herniation and fractures of the thoracolumbar junction have been adapted for use as a minimally invasive thoracoscopic-assisted approach (TAA) for decompression and stabilization of metastatic spine disease. ${ }^{18}$

In this report, we describe the treatment of 12 patients with a mini-open TAA for metastatic disease at the thoracolumbar junction with an analysis of procedural and long-term outcomes. We hypothesize that use of the miniopen TAA results in significant improvement in preoperative pain and neurological outcomes after surgery and compares favorably with traditional and novel posterior techniques.

\section{Methods \\ Patient Population}

We retrospectively identified patients treated with a mini-open TAA for metastatic disease at the thoracolumbar junction by the senior author (M.H.S.) during a 14-year period from 2004 through 2016. We collected data on age, sex, levels affected, pathology, operative time, estimated blood loss (EBL), length of stay, duration of follow-up, and pre- and postoperative visual analog scale (VAS) scores and Frankel grades from the medical records.

\section{Operative Technique}

Preoperative Considerations

For this approach, any history of surgery in the thoracic cavity, chest wall trauma requiring surgery, or significant infection requiring video-assisted thoracoscopic surgery or thoracotomy are contraindications because they can lead to pleural adhesions. Additionally, the use of singlelung ventilation prohibits any patients with severe reactive airway disease, such as chronic obstructive pulmonary disease or asthma, from undergoing this procedure..$^{11,30}$ Patients require general endotracheal anesthesia and are usually intubated with a double-lumen endotracheal tube to achieve single-lung ventilation. Intravenous high-dose steroids were used in patients with symptomatic spinal cord compression or myelopathy. ${ }^{20}$ Consultation with an interventional specialist for preoperative embolization was sought for every case. ${ }^{14}$

\section{Patient Positioning}

The procedure has been described in detail in a previous publication. ${ }^{18}$ The approach must be individualized based on the vascular anatomy of the great vessels (i.e., aorta and inferior vena cava), but, typically, a left-sided approach is used to access the thoracolumbar junction (T11L2) whereas a right-sided approach is used for the upper and middle thoracic spine (T3-10). ${ }^{6}$ The patient is placed in the lateral decubitus position on a radiolucent table with 4-point support, and an axillary roll is placed, with the arm in a Krause armrest. Intraoperative fluoroscopy is used to verify patient position, as well as the parallel alignment of the spine to the operating table.

\section{Thoracoscopic Access and Exposure}

This technique involves the use of 4 access sites around the lesion-one for the camera, one for retraction, one for suction/irrigation, and one for working access-which, along with the anatomical structures of interest, are marked on the skin surface (Fig. 1). The working port is placed directly over the lesion of interest. The endoscopic port is positioned 2-3 intercostal spaces from the working port to optimize image quality. The suction/irrigation portal is ventral and cranial to the working portal. The retraction portal allows for safe retraction of the lung and the diaphragm and is ventral and caudal to the working portal. The "mini-open" refers to the enlarged size $(3-4 \mathrm{~cm})$ of the working portal in comparison with the other portals $(1.5-2 \mathrm{~cm})$; this allows for improved cephalad-to-caudal access across the vertebral body of interest, and it facilitates placement of an expandable cage for reconstruction. ${ }^{26}$

After the first portal is opened bluntly to minimize injury to the underlying lung and the pleural space bluntly dissected, the parietal pleura is opened, the collapsed lung is visualized directly, the initial trocar is inserted, and the $30^{\circ}$ endoscope is introduced into the thoracic cavity. The remaining 3 trocar sites are placed under endoscopic visualization. The image is oriented in a manner so the vertebral body in question is located in the lower edge of the video monitor. Next, a pleural flap is elevated and the vertebral bodies and discs are exposed.

\section{Placement of Screws and Instrumentation}

Anterior fixation in all cases used the MACS TL endoscopic anterolateral plate (Aesculap), which includes 2 clamps and 4 screws (2 anterior stabilization screws and 2 posterior polyaxial vertebral body screws). One clamp and 2 screws are used at each vertebral body adjacent to the diseased vertebra (Fig. 2). Using a short K-wire placed under fluoroscopic guidance as a guide, a cannulated awl is used to decorticate each screw entry point. The polyaxial screw clamp is assembled and inserted, and the Kwire is removed after the screw has engaged the cortical surface. After the polyaxial posterior screws have been placed above and below the diseased vertebral body, the clamps are oriented perpendicular to the anterior aspect of the vertebral body with careful consideration given to the surrounding great vessels.

\section{Corpectomy and Spinal Canal Decompression}

Discectomy and corpectomy are performed in a similar 


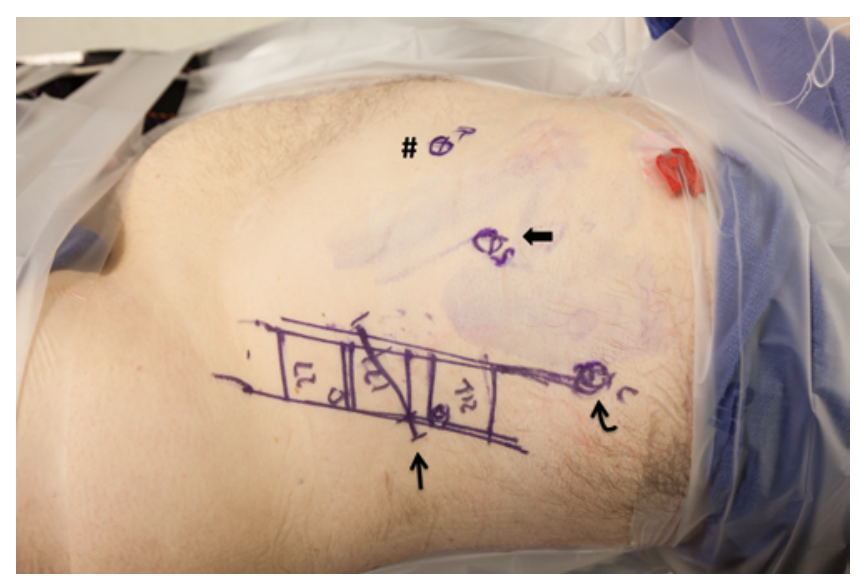

FIG. 1. Projection of 4 portal access sites. The thoracic cavity was marked with a projection of the T-12, L-1, and L-2 vertebral bodies as determined by fluoroscopy. Four portals were also marked as follows: 1) the working port placed directly over the lesion of interest (L-1, straight arrow); 2) the camera port located 2 levels above the working port (curved arrow); 3) a suction port along the same rib (block arrow); and 4) retraction port (pound sign).

manner to an open procedure. The vertebral body in question is removed using a median corpectomy with straight and curved osteotomes (Fig. 3). These procedures allow for direct decompression and visualization of the anterior spinal cord.

\section{Interbody Reconstruction and Endoscopic Stabilization}

The thoracolumbar junction is reconstructed with an expandable cage inserted under direct fluoroscopic visualization after the complete corpectomy (Fig. 4). ${ }^{26}$ Once the cage is expanded, allograft is packed around the cage itself, and the anterolateral plate is placed over the posterior polyaxial screws. The screw/plate construct is then locked and torqued.

\section{Placement of Chest Tube and Closure}

The diaphragm is sutured closed, and the operative field and the entire thoracic cavity are irrigated. A $24 \mathrm{Fr}$ chest tube is placed through the inferolateral port or the lateral suction port under direct or thoracoscopic visualization, and the lung is reinflated.

\section{Statistical Analysis}

Differences in patient-reported clinical outcomes before and after surgery were compared using paired t-tests; $\mathrm{p}<0.05$ was considered statistically significant.

\section{Results}

We identified 12 patients who met the inclusion criteria of mini-open TAA for metastatic disease at the thoracolumbar junction. Preliminary outcomes for 5 of these patients were reported previously. ${ }^{18}$ The mean age of patients in this series was 59 years (range 53-77 years) (Table 1). A majority of patients ( 9 of 12 , or $75 \%$ ) underwent a leftsided mini-open TAA to the thoracolumbar junction. In the 12 patients, the mean EBL was $613 \mathrm{ml}$, and the mean duration of the procedure was 234 minutes (3.8 hours). Three patients required intraoperative blood transfusion; one patient became hemodynamically unstable during surgery and was found to have a splenic injury on postoperative abdominal imaging requiring splenectomy the same day. ${ }^{5}$ All patients were extubated with no subsequent respiratory complications such as pneumonia, pleural effusion, or hemo-/pneumothorax. Four patients underwent an additional posterior surgery, after the mini-open TAA, for supplemental pedicle screw fixation, not decompression; of these, 2 patients suffered delayed posterior wound infections treated with surgical debridement and antibiotics. There were no wound complications associated with the mini-open TAA.

All 12 patients had significant improvement in their postoperative pain scores compared with their preop-
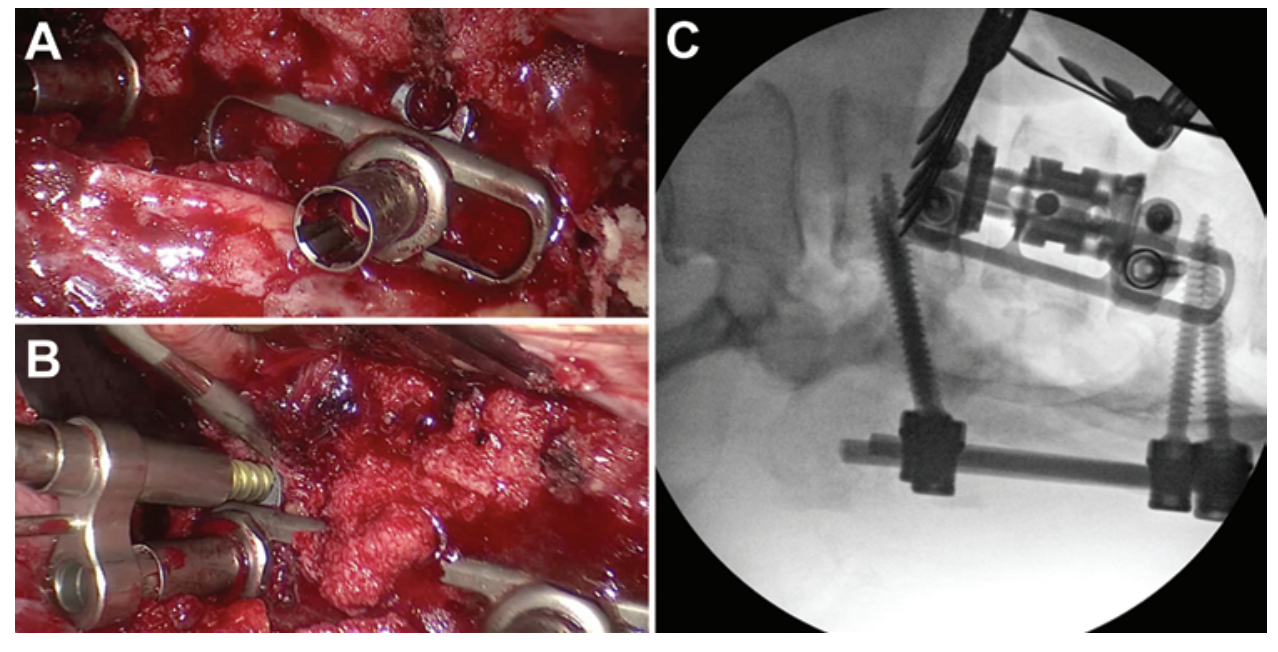

FIG. 2. Anterior fixation with the MACS TL endoscopic plate. A: Posterior polyaxial screws are placed in the vertebral body above and below. After the corpectomy is completed, the plate is placed across the screws. B: Following placement of the plate, the anterior stabilization screws are placed and the posterior screws are tightened. C: An intraoperative lateral radiograph shows the final placement of the anterior and posterior screws and the plate. 

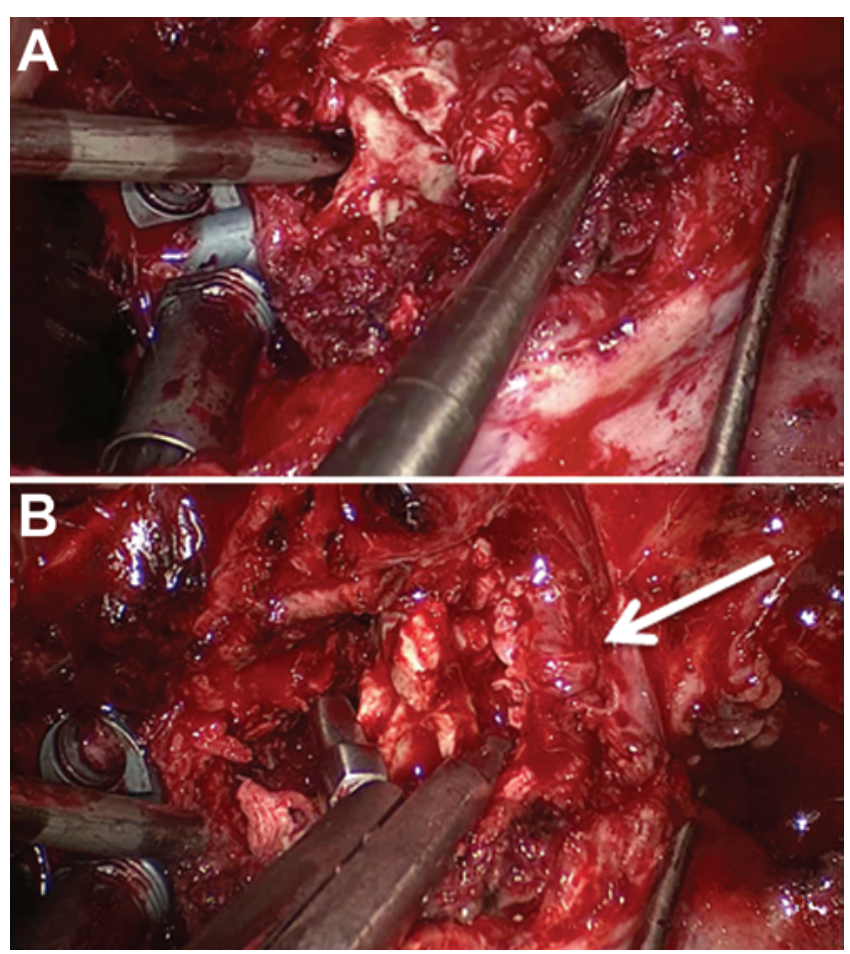

FIG. 3. Discectomy and corpectomy. A: The discs are incised and removed with rongeurs, and this is followed by a median corpectomy using straight and curved osteotomes. B: Removal of the vertebral body (arrow).

erative pain scores $(p<0.001)$. No patients had worsening neurological function after surgery; in fact, of the 7 patients who presented with neurological dysfunction, 6 had improved neurological function after surgical intervention (86\%), with the other patient maintaining the preoperative level of dysfunction. The median length of stay in the hospital was 7.5 days (range 5-21 days). The patient with a 21-day hospitalization suffered a posteriorapproach wound infection requiring debridement and antibiotic therapy.

There were no hardware failures requiring reoperation during the mean follow-up of 10 months (range 1-45 months). Nine of the 12 patients died as a result of their primary illness.

\section{Illustrative Case \\ Case 2}

History

A 58-year-old man with a medical history of central nervous system lymphoma presented with acute back pain and decreased lower-extremity function. MRI of the lumbar spine showed an L-1 compression fracture for which he subsequently underwent kyphoplasty and biopsy at an outside institution. The pathological identification of the biopsied material was plasmacytoma. The patient continued to experience unrelenting back pain (VAS score of 9/10). $\mathrm{CT}$ and MRI of the lumbar spine showed an L-1 pathological fracture (Fig. 5) with 50\% loss of height with cement extrusion from the kyphoplasty into the left-sided anterolateral soft tissues, as well as $5 \mathrm{~mm}$ of retropulsion into the spinal canal. The patient's motor function was preserved; however, his gait was impaired (Frankel Grade D). ${ }^{10}$

\section{Surgical Intervention and Postoperative Course}

The surgery was carried out in 2 stages: a T12-L2 posterior fusion was followed by a mini-open TAA for L-1 corpectomy, with successful removal of the kyphoplasty cement and vertebral body (Video 1).

VIDEO 1. Video demonstrating a mini-open TAA for resection of kyphoplasty cement and vertebral body resection with anterior reconstruction. Final pathology diagnosis was plasmacytoma. Copyright Department of Neurosurgery, University of Utah.

Published with permission. Click here to view.

We were able to completely remove the displaced cement en bloc using this approach.

The patient did well postoperatively with maintained motor strength in his lower extremities with an improved gait tolerance (Frankel Grade E) and significantly improved pain (VAS score of 0/10). Final pathological results were consistent with plasmacytoma. After surgery, oncological evaluation showed that the patient had Stage IIA kappa light chain multiple myeloma for which he began treatment. At his 1-month and 1-year clinical follow-up examinations, he was ambulatory and had continued good hardware and bony alignment with no recurrent tumor.

\section{Discussion}

We have described the successful surgical treatment of
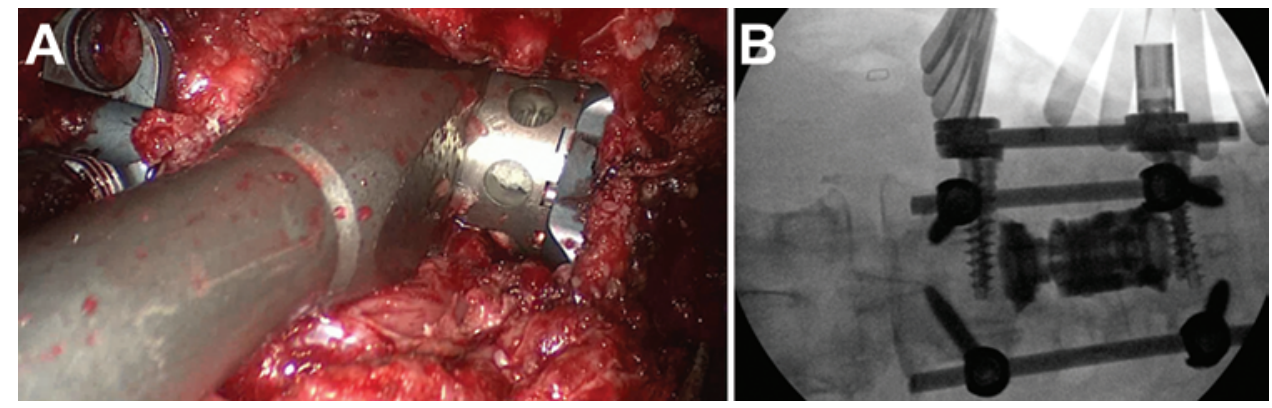

FIG. 4. Placement of a cage following corpectomy. A: Placement of the cage with neutral end pieces. Prior to insertion, the cage was packed with demineralized bone putty and fresh cancellous bone. B: Intraoperative radiograph showing final positioning of the cage. 
TABLE 1. Operative and follow-up data for 12 patients with metastatic disease of the thoracolumbar junction in whom a mini-open TAA was used for ventral decompression and stabilization*

\begin{tabular}{|c|c|c|c|c|c|c|c|c|c|}
\hline \multirow{2}{*}{$\begin{array}{l}\text { Case } \\
\text { No. }\end{array}$} & \multirow{2}{*}{$\begin{array}{c}\text { Age (yrs), } \\
\text { Sex }\end{array}$} & \multirow{2}{*}{$\begin{array}{l}\text { Level of } \\
\text { Disease }\end{array}$} & \multirow[b]{2}{*}{ Pathological Diagnosis } & \multirow{2}{*}{$\begin{array}{l}\text { Side of } \\
\text { Approach }\end{array}$} & \multirow{2}{*}{$\begin{array}{l}\text { Op Time } \\
\text { (mins) }\end{array}$} & \multirow{2}{*}{$\begin{array}{c}\text { EBL }(\mathrm{ml}) / \\
\text { Transfusion }\end{array}$} & \multirow{2}{*}{$\begin{array}{l}\text { LOS } \\
\text { (days) }\end{array}$} & \multicolumn{2}{|c|}{ VAS Score, Frankel Grade } \\
\hline & & & & & & & & Preop & Postop \\
\hline 1 & $53, M$ & $T-10$ & Plasmacytoma & Rt & 191 & $800 / n o$ & 9 & $8, \mathrm{E}$ & $1, \mathrm{E}$ \\
\hline 2 & $58, \mathrm{M}$ & L-1 & Plasmacytoma & Lt & 179 & 500/yes & 15 & $9, \mathrm{D}$ & $0, \mathrm{E}$ \\
\hline 3 & $55, M$ & L-1 & Squamous cell carcinoma & Lt & 217 & $300 /$ no & 7 & $10, \mathrm{D}$ & $0, E$ \\
\hline $4 \dagger$ & $60, M$ & $T-12$ & Epithelioid tumor & Lt & 190 & 500/yes & 7 & $4, D$ & $3, E$ \\
\hline 5 & $61, M$ & L-1 & Thyroid carcinoma & Lt & 278 & 500/no & 6 & $10, D$ & $6, D$ \\
\hline 6 & $54, \mathrm{M}$ & $\mathrm{T}-12$ & Lung adenocarcinoma & Lt & 180 & $200 /$ no & 5 & $3, D$ & $0, E$ \\
\hline 7 & $52, F$ & L-1 & Breast carcinoma & $\mathrm{Lt}$ & 240 & $500 /$ no & 8 & $8, C$ & $4, E$ \\
\hline 8 & $48, M$ & L-1 & Renal cell carcinoma & $\mathrm{Lt}$ & 270 & $800 /$ no & 11 & $8, E$ & $4, E$ \\
\hline 9 & $77, \mathrm{~F}$ & L-1 & Renal cell carcinoma & $\mathrm{Lt}$ & 272 & 1500/yes & 21 & $8, E$ & $0, E$ \\
\hline 10 & $67, \mathrm{~F}$ & $\mathrm{~T}-11$ & Breast carcinoma & Rt & 300 & $350 /$ no & 8 & $7, E$ & $3, \mathrm{E}$ \\
\hline 11 & $62, M$ & $\mathrm{~T}-11$ & Esophageal adenocarcinoma & $\mathrm{Lt}$ & 250 & $500 /$ no & 6 & $3, E$ & $0, \mathrm{E}$ \\
\hline 12 & $61, M$ & $T-10$ & Prostate adenocarcinoma & Rt & 240 & $900 /$ no & 6 & $8, D$ & $0, \mathrm{E}$ \\
\hline
\end{tabular}

LOS $=$ length of stay.

* Preliminary results from Cases $7,8,10,11$, and 12 were reported previously. ${ }^{18}$

$\dagger$ Indicates the patient who underwent splenectomy postoperatively for splenic injury. This case was previously reported. ${ }^{5}$

12 patients in whom a mini-open TAA was used to treat metastatic tumors at the thoracolumbar junction. This approach and this method for treating metastatic disease to the vertebral column have been previously described, ${ }^{18}$ but this report focuses on the aspect of follow-up and improvement in pain scores and function.

In the setting of metastatic disease with epidural compression, surgery with focus on decompression of the posterior elements has been largely abandoned because laminectomy alone or in combination with radiotherapy did not differ from radiotherapy alone..$^{13,15,33}$ Posterior decompression likely failed because a majority of spinal metastases are located in the vertebral body, ventral to the spinal cord. Additionally, laminectomy in the setting of diseased anterior and middle columns can lead to severe instability. Because of these concerns, anterior approaches are ideal for achieving more direct decompression by addressing the pathological area. In addition, an anterior approach also allows for immediate interbody reconstruction and stabilization. ${ }^{18}$

An anterior approach to the thoracolumbar junction allows for direct access to the majority of the disease burden, located in the ventral portion of the vertebral body, with minimal disruption of the neural elements. The traditional anterior access involved the use of an open thoracotomy, but less invasive techniques have been developed to minimize surgical morbidity. Thoracoscopic procedures have complication rates between $0 \%$ and $5.4 \%,{ }^{2-4,6,18,19,26}$ whereas open thoracotomy morbidity rates are between $14 \%$ and $29.5 \% .^{2-4,24,32}$ Specifically, the combined complication rates of postoperative pneumothorax, pleural effusion, and intercostal neuralgia for the thoracoscopic approach are reported to be $5.4 \%$ compared with $14 \%$ for the open approach. ${ }^{3}$ Furthermore, the mortality rate for open thoracotomy for tumor is $8.2 \%,{ }^{32}$ whereas no deaths have been reported for thoracoscopic surgery. ${ }^{4,18}$

The mini-open TAA has also been associated with other substantial clinical benefits, including reduced postop-
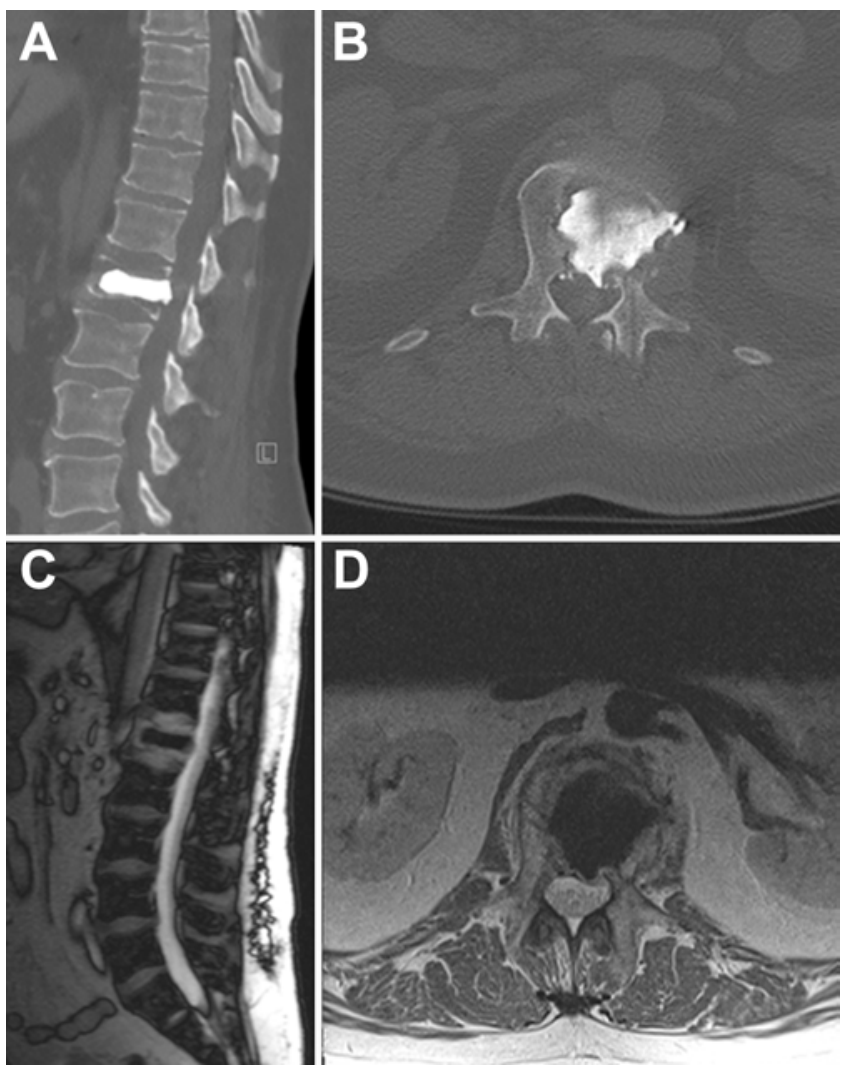

FIG. 5. Case 2. CT and MRI studies of the thoracolumbar spine in a 58-year-old man. A: Lateral CT scan of the kyphoplasty cement within the L-1 vertebral body and extruding into the spinal canal. B: Axial CT scan of cement extruded into the left paraspinous soft tissues and posteriorly into the spinal canal. C: Lateral T2-weighted MR image of the kyphoplasty cement within L-1. D: Axial T2-weighted MR image of the kyphoplasty cement within L-1. 
erative pain, shorter intensive care unit and hospital stays, shorter recovery time, and faster return to activity. ${ }^{9,17,22}$ Postoperative pain after thoracoscopic surgery is significantly reduced compared with that from open surgery. ${ }^{18}$ Postoperative analgesic therapy dosages and durations are reported to decrease by $42 \%$ and $31 \%$, respectively. ${ }^{2-4}$ Whereas reported rates of chronic pain with open thoracotomy range from $7 \%$ to $55 \%,{ }^{3}$ favorable rates between $4 \%$ and $35 \%$ are associated with thoracoscopic-assisted surgery. All 12 patients in our series had significant improvement in their postoperative pain scores in comparison with their preoperative pain scores $(p<0.001)$. No patients suffered from worsening neurological function after surgery; in fact, of the 7 patients who presented with neurological dysfunction, 6 improved after surgical intervention (86\%), with the other patient maintaining the same level of dysfunction. The hospital length of stay is also lower for the TAA than for open approaches. In a series of patients who underwent thoracoscopic tumor surgery, ${ }^{18}$ the median length of stay in the hospital was 7 days (range 4-10 days) compared with a median of 9 days (range 4-57 days) for patients who underwent open thoracotomy for tumor resection. ${ }^{32}$ The length of stay in the present series compares well with that of previous thoracoscopic reports, with a median of 7.5 days (range 5-21 days) (Table 1).

Thoracoscopic approaches also allow for a reduction of blood loss. The mean EBL for thoracoscopic spine surgery in trauma patients ranges from 250 to $450 \mathrm{ml},{ }^{3}$ which is lower than the EBL associated with many posterior fusion procedures. In our series, the mean EBL was slightly higher, at $613 \mathrm{ml}$, although it still compares favorably with that reported in a study of open thoracotomy cases for tumor, which reported 1-L median EBL. ${ }^{32}$ The EBL of 613 $\mathrm{ml}$ is also lower than that reported for newer techniques such as the mini-open posterior thoracic corpectomy with cage reconstruction (mean $917.7 \mathrm{ml}$ ) and the traditional open posterior thoracic corpectomy (mean $1697 \mathrm{ml}$ ). ${ }^{23}$ Thus, the mini-open TAA can be used to decrease perioperative morbidity while achieving the goal of ventral decompression and stabilization to improve pain, preserve neurological function, and provide stability. The results of a study comparing open and thoracoscopic corpectomy, which included metastatic tumor patients, confirmed that patients undergoing mini-open TAA required fewer blood transfusions. ${ }^{27}$

There are limitations to the mini-open TAA to the thoracolumbar junction. As noted, serious complications of the thoracoscopic procedure can include persistent pneumothorax, chyle thorax, intercostal neuralgia, cerebrospinal fluid fistula, lung injury, and injury to the great vessels. In this series, one patient became hemodynamically unstable during surgery despite a clean operating field; postoperative abdominal imaging revealed a splenic injury that required splenectomy, and the patient made an excellent recovery. ${ }^{5}$ This was due to diaphragm retraction; thus, hemodynamic instability while performing a mini-open TAA should be investigated with abdominal and thoracic imaging.

As with all minimally invasive approaches, a learning curve exists and can be steep for this procedure. In our opinion, inexperience should not prohibit physicians from learning this technique for its initial as well as the expanded indications. Initially, operative times are expected to increase to an average of 5 hours or more, ${ }^{1-4,18,19,28}$ but once the procedure has been mastered, total surgical time for resection and reconstruction decreases to 2.5 to 3 hours in cases of trauma ${ }^{3}$ and to 4 hours for tumor. ${ }^{18,28}$ In the present series, the mean operative time was less than 4 hours. In skilled hands, the rate of conversion to an open thoracotomy is $1 \%$ or less. ${ }^{2}$

In a recent report, $\mathrm{Chou}$ and $\mathrm{Lu}^{8}$ discussed the use of a mini-open transpedicular corpectomy for metastatic lesions; additional reports have shown the mini-open transpedicular procedure to be associated with less blood loss and shorter hospital stay than open transpedicular procedures, with nonsignificant trends toward lower infection and complication rates. ${ }^{23}$ The blood loss is still considerably higher than that documented in our series in which the mini-open TAA was used to acces the thoracolumbar junction. Although these procedures may be considered in the setting of thoracolumbar junction metastatic disease, injury to the spinal cord, blood loss, surgical time, and perioperative morbidity in mini-open TAA, mini-open transpedicular corpectomy, and traditional open posterior corpectomy procedures need to be evaluated.

The results of the current series demonstrate that the mini-open TAA to the thoracolumbar junction can allow for placement of an interbody cage and anterolateral plate in patients with metastatic spine disease. Additionally, no patients experienced delayed hardware failure requiring reoperation in a mean follow-up period of 10 months (range 1-45 months). Limitations of the current series include its small sample size and lack of direct comparison with other surgical approaches. Nonetheless, the miniopen TAA should be considered when treating patients with metastatic spine disease.

\section{Circumferential Fusion}

Four patients underwent an additional posterior surgical fixation. All 4 posterior procedures were planned but were performed in a delayed manner during the same hospitalization. The decision was made ad hoc based on the degree of preoperative kyphosis $\left(>30^{\circ}\right)$, bone quality on preoperative imaging and as observed intraoperatively during the mini-open TAA, and the desire to avoid rigid external orthosis postoperatively. Avoidance of bracing postoperatively is used to minimize skin irritation and formation of decubitus ulcers.

In 2 of the 4 patients who underwent additional posterior fixation, a surgical site infection (SSI) developed, although none of the patients had wound complications from the mini-open TAA. One 52-year-old woman with metastatic breast carcinoma and a body mass index of 16 was malnourished and cachectic on her initial presentation. In addition, she had a significant smoking history. She also presented with neurological deficits, and thus had been on intravenous high-dose steroid therapy, likely contributing to her infection. The second patient was a 77-year-old woman with a history of renal cell carcinoma who was also malnourished and cachectic on admission, with recent weight loss, although she did have a normal body mass index. Given her presentation with pain, uri- 
nary retention, and radiographic evidence of epidural disease, she was also started on intravenous high-dose steroid therapy. The risk factors for SSI are well known in this population; Sugita et al. demonstrated that patient prognosis, postoperative ambulatory function, and preoperative radiation were risk factors for SSI in patients with spinal metastases. ${ }^{31}$ Neither of the patients with SSI had preoperative radiotherapy and both were ambulatory after surgical intervention.

In a comparison of the mini-open and open posterior thoracic corpectomy with cage reconstruction, Lau and $\mathrm{Chou}^{23}$ found a difference between infection rates $(17.9 \%$ in the open group vs $9.5 \%$ in the mini-open group) that was not statistically significant. This high rate of posterior infection is likely reflected on our small cohort of patients who underwent posterior stabilization.

\section{Conclusions}

The mini-open TAA to the thoracolumbar junction for metastatic disease is a durable procedure with reduced morbidity compared with traditional open thoracotomy for ventral decompression and fusion. The mini-open TAA can be used alone or in conjunction with posterior fixation, depending on degree of kyphosis and bone quality. This small series demonstrates a significant improvement in preoperative pain and neurological symptoms, suggesting that this technique can be considered when treating complex metastatic disease at the thoracolumbar junction.

\section{Acknowledgments}

We thank Kristin Kraus, MSc, for editorial assistance with this paper and Vance Mortimer for video editing and preparation.

\section{References}

1. Amini A, Beisse R, Schmidt MH: Thoracoscopic spine surgery for decompression and stabilization of the anterolateral thoracolumbar spine. Neurosurg Focus 19(6):E4, 2005

2. Balabhadra R, Kim D, Potulski M, Beisse R: Thoracoscopic decompression and fixation (MACS-TL), in Kim D, Fessler RG, Regan JJ (eds): Endoscopic Spine Surgery and Instrumentation: Percutaneous Procedures. New York: Thieme, 2005, pp 180-198

3. Beisse R: Endoscopic anterior repair in spinal trauma, in Regan J, Lieberman I (eds): Atlas of Minimal Access Spine Surgery. St. Louis: Quality Medical Publishing, 2004

4. Beisse R: Thoracoscopically assisted anterior approach to thoracolumbar fractures, in Mayer HM (ed): Minimally Invasive Spine Surgery. Berlin: Springer, 2006, pp 203-214

5. Binning MJ, Bishop F, Schmidt MH: Splenic rupture related to thoracoscopic spine surgery. Spine (Phila Pa 1976) 35:E654-E656, 2010

6. Böhm P, Huber J: The surgical treatment of bony metastases of the spine and limbs. J Bone Joint Surg Br 84:521-529, 2002

7. Byrne TN: Spinal cord compression from epidural metastases. N Engl J Med 327:614-619, 1992

8. Chou D, Lu DC: Mini-open transpedicular corpectomies with expandable cage reconstruction. Technical note. J Neurosurg Spine 14:71-77, 2011

9. Dickman CA, Rosenthal D, Karahalios DG, Paramore CG, Mican CA, Apostolides PJ, et al: Thoracic vertebrectomy and reconstruction using a microsurgical thoracoscopic approach. Neurosurgery 38:279-293, 1996

10. El Masry WS, Tsubo M, Katoh S, El Miligui YH, Khan A: Validation of the American Spinal Injury Association (ASIA) motor score and the National Acute Spinal Cord Injury Study (NASCIS) motor score. Spine (Phila Pa 1976) 21:614-619, 1996

11. Fourney DR, Gokaslan ZL: Anterior approaches for thoracolumbar metastatic spine tumors. Neurosurg Clin N Am 15:443-451, 2004

12. Gerszten PC, Welch WC: Current surgical management of metastatic spinal disease. Oncology (Williston Park) 14:1013-1024, 1029-1030, 2000

13. Gilbert RW, Kim JH, Posner JB: Epidural spinal cord compression from metastatic tumor: diagnosis and treatment. Ann Neurol 3:40-51, 1978

14. Gottfried ON, Schloesser PE, Schmidt MH, Stevens EA: Embolization of metastatic spinal tumors. Neurosurg Clin $\mathbf{N}$ Am 15:391-399, 2004

15. Greenberg HS, Kim JH, Posner JB: Epidural spinal cord compression from metastatic tumor: results with a new treatment protocol. Ann Neurol 8:361-366, 1980

16. Harrington KD: Metastatic tumors of the spine: diagnosis and treatment. J Am Acad Orthop Surg 1:76-86, 1993

17. Kaiser LR: Video-assisted thoracic surgery. Current state of the art. Ann Surg 220:720-734, 1994

18. Kan P, Schmidt MH: Minimally invasive thoracoscopic approach for anterior decompression and stabilization of metastatic spine disease. Neurosurg Focus 25(2):E8, 2008

19. Khoo LT, Beisse R, Potulski M: Thoracoscopic-assisted treatment of thoracic and lumbar fractures: a series of 371 consecutive cases. Neurosurgery 51 (5 Suppl):S104-S117, 2002

20. Klimo P Jr, Kestle JR, Schmidt MH: Clinical trials and evidence-based medicine for metastatic spine disease. Neurosurg Clin N Am 15:549-564, 2004

21. Klimo P Jr, Schmidt MH: Surgical management of spinal metastases. Oncologist 9:188-196, 2004

22. Landreneau RJ, Mack MJ, Hazelrigg SR, Dowling RD, Acuff TE, Magee MJ, et al: Video-assisted thoracic surgery: basic technical concepts and intercostal approach strategies. Ann Thorac Surg 54:800-807, 1992

23. Lau D, Chou D: Posterior thoracic corpectomy with cage reconstruction for metastatic spinal tumors: comparing the mini-open approach to the open approach. J Neurosurg Spine 23:217-227, 2015

24. Oskouian RJ Jr, Johnson JP: Vascular complications in anterior thoracolumbar spinal reconstruction. J Neurosurg 96 (1 Suppl):1-5, 2002

25. Patchell RA, Tibbs PA, Regine WF, Payne R, Saris S, Kryscio RJ, et al: Direct decompressive surgical resection in the treatment of spinal cord compression caused by metastatic cancer: a randomised trial. Lancet 366:643-648, 2005

26. Ragel BT, Amini A, Schmidt MH: Thoracoscopic vertebral body replacement with an expandable cage after ventral spinal canal decompression. Neurosurgery 61 (5 Suppl 2):317-323, 2007

27. Ragel BT, Kan P, Schmidt MH: Blood transfusions after thoracoscopic anterior thoracolumbar vertebrectomy. Acta Neurochir (Wien) 152:597-603, 2010

28. Ray WZ, Schmidt MH: Thoracoscopic vertebrectomy for thoracolumbar junction fractures and tumors: surgical technique and evaluation of the learning curve. Clin Spine Surg [epub ahead of print], 2016

29. Schmidt MH, Klimo P Jr, Vrionis FD: Metastatic spinal cord compression. J Natl Compr Canc Netw 3:711-719, 2005

30. Schmidt MH, Larson SJ, Maiman DJ: The lateral extracavitary approach to the thoracic and lumbar spine. Neurosurg Clin N Am 15:437-441, 2004 
31. Sugita S, Hozumi T, Yamakawa K, Goto T, Kondo T: Risk factors for surgical site infection after posterior fixation surgery and intraoperative radiotherapy for spinal metastases. Eur Spine J 25:1034-1038, 2016

32. Walsh GL, Gokaslan ZL, McCutcheon IE, Mineo MT, Yasko AW, Swisher SG, et al: Anterior approaches to the thoracic spine in patients with cancer: indications and results. Ann Thorac Surg 64:1611-1618, 1997

33. Young RF, Post EM, King GA: Treatment of spinal epidural metastases. Randomized prospective comparison of laminectomy and radiotherapy. J Neurosurg 53:741-748, 1980

\section{Disclosures}

Dr. Schmidt is a consultant for Ulrich Medical USA.

\section{Author Contributions}

Conception and design: Schmidt, Ravindra. Acquisition of data: all authors. Analysis and interpretation of data: Schmidt, Ravindra, Brock. Drafting the article: Ravindra, Brock. Critically revising the article: all authors. Reviewed submitted version of manuscript: all authors. Approved the final version of the manuscript on behalf of all authors: Schmidt. Statistical analysis: Ravindra. Study supervision: Schmidt.

\section{Supplemental Information Videos \\ Video 1. https://vimeo.com/170956755. \\ Correspondence}

Meic H. Schmidt, Department of Neurosurgery, Clinical Neurosciences Center, University of Utah, $175 \mathrm{~N}$ Medical Dr. East, Salt Lake City, UT 84132. email: neuropub@hsc.utah.edu. 